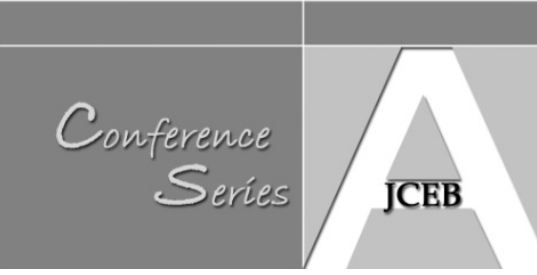

\title{
Sustainable Retirement Living: What Matters?
}

\author{
Jake Barker ${ }^{1}$, Bo Xia ${ }^{2}$, Jian Zou ${ }^{1}$ and George Zillante ${ }^{1}$ \\ ${ }^{1}$ University of South Australia; ${ }^{2}$ Queensland University of Technology
}

\begin{abstract}
There is a growing demand for sustainable retirement villages in Australia due to an increasing number of ageing population and public acceptance of sustainable development. This research aims to gain a better understanding of retirees' understanding about sustainable retirement living and their attitudes towards sustainable developments via a questionnaire survey approach. The results showed that the current residents of retirement villages are generally very conscious of unsustainable resource consumption and would like their residences and community to be more environmentally friendly and energy efficient. The cost of energy supply is a concern to majority of respondents. However there is a certain level of concerns from residents too on the extra cost of going green in their residence. Education is required to residents about recycling household waste and how to use available facilities. A better understanding of retirees' awareness and attitudes towards sustainability issues helps to improve the sustainable developments of retirement villages in the future.
\end{abstract}

Keyword: Sustainability, Retirement Living, South Australia

\section{INTRODUCTION}

There is a growing demand for sustainable buildings worldwide due to an increasing level of public awareness on the environmental and social impacts of the building sector. It is well recognized that the building sector is one of biggest energy consumers and Greenhouse gas emitters (e.g. Zuo et al. 2012). According to the World Business Council for Sustainable Development (WBCSD 2007), 40\% of energy is consumed by buildings. Construction activities are also responsible for the dust, noise, water pollution and waste on construction sites. As a consequence, all sectors should make efforts to improve the sustainability performance of their buildings. For instance, the Green Building Council of Australia has developed a number of green building rating tools to foster the green building developments. These rating tools cover a wide range of types of buildings such as: commercial building, multi-unit residential building, retail building and institutional buildings (GBCA 2012). Indeed, the building sector is identified by the WBCSD as one of nine key sectors contributing toward a sustainable future. In the Vision 2050, WBCSD defined a vision for the building sector to be "close to zero net energy buildings" by 2050 (WBCSD 2010, p.13). To achieve this goal, it is essential to raise the awareness of all stakeholders by means of education (Chan et al. 2009).

The last century has witnessed the aging population in Australia. According to the statistics provided by the Australian Bureau of Statistics, 14.8\% of Australians were aged 65 years and over in 2007 (see Fig.1). The Australian Bureau of Statistics has predicted that this proportion will double in 2101, reaching 11million (ABS 2010). According to the Retirement Village Association, this "population growth in older demographic segments" presents "a looming crisis in respect to how we house and care for older Australians" (RVA 2011, p.3). Therefore, retirement accommodation plays an important role for achieving sustainable development in the housing sector. 


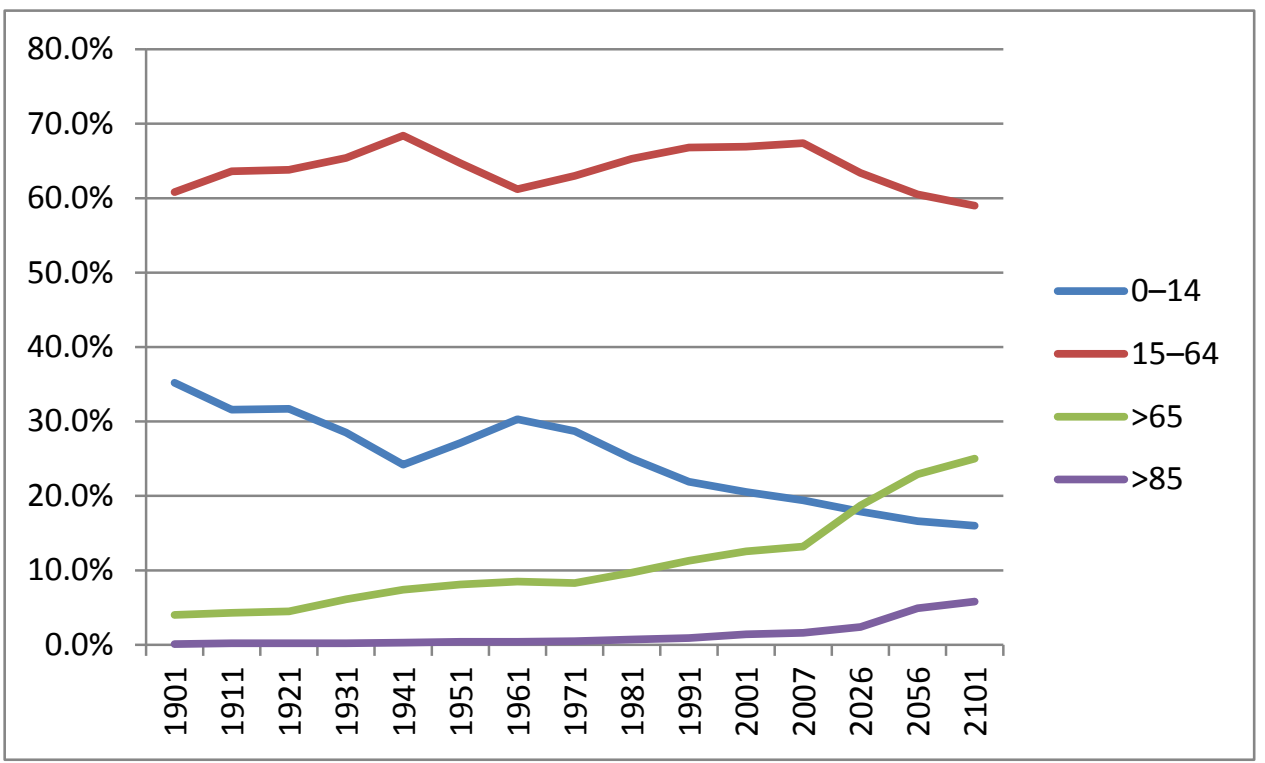

Figure 1: Demographic profile of Australian population growth. Source: ABS (2010)

There are various housing options for seniors, ranging from independent-living alternatives through to high-level care. The retirement villages accommodated more than 5\% of Australians aged over 65 years and more than 10\% of those over 75 (RVA 2011, p.3). In particular, some Australian States already have significantly higher rates, with Western Australia and South Australia being approximately 7\% and 8\% respectively (Retirement Village Association and Aged and Community Services Association of NSW and ACT, 2010).Therefore, this study placed on focus on retirement village as the option of retirement living.

There are ample research literatures available in relation to sustainability practices in construction context such as adoption of renewable energy, water efficiency and waste recycling (e.g. McCormack et al. 2007; Tam 2008; Chan et al. 2009; Ilha et al. 2009). However, the extensive literature review shows that there is very little research into applying sustainable construction practices specifically into retirement accommodation developments. With an ageing population in Australia, the demand for retirement accommodation is on the rise. This research aims to investigate the retirees' understanding about sustainable retirement living and their attitudes towards environmental sustainability practices.

\section{RESEARCH METHODOLOGY}

A survey has been undertaken, using a questionnaire, on retirement village residents to investigate their awareness of attitudes towards sustainability issues in retirement villages. The respondents were randomly selected from residents of retirement villages developed by ECH Incorporated (ECH), one of largest not-for-profit providers of affordable retirement housing in South Australia. The survey questions covered concerns on rising energy cost, environmental protection, willingness to accept, willingness to pay and incorporation of renewable energy into residence, etc. The instrument was pilot tested with a comparatively small group of residence of retirement villages. The results are positive therefore no major changes are needed. The survey was distributed to 160 residents from various retirement developments throughout South Australia. The selection criteria of survey respondents are:

- They are retirees aged over 65 years

Barker, J., Xia, B., Zou, J. and Zillante, G. (2012) 'Sustainable retirement living: what matters?', Australasian Journal of Construction Economics and Building, Conference Series, 12 (1) 56-61 
- They are living independently

- They are living in self-contained, unit style accommodation

- Their dwellings are within retirement developments throughout South Australia

The total number of 76 surveys were returned and with a response rate of $47.5 \%$. Around $50 \%$ of residents surveyed had lived in their residences for more than 10 years.

\section{Results}

\section{Cost of energy supply}

It is important to know if the cost of energy supply is a concern to the residents of retirement living. Interestingly, of the residents surveyed 54\% indicated that the cost of energy supply was a concern. Only $26 \%$ did not show concerns about the cost of energy supply. The rising energy bill may play a role to motivate more sustainable development and consumptions.

\section{Environmental protection}

One of the priorities of this research was to gain an insight into whether protecting the environment was a priority of the residents of retirement living. In response to this question, 92\% of residents surveyed indicated that they believe it is important to protect the environment. Interestingly $8 \%$ said they were unsure and no one resident disagreed that protecting the environment was important.

\section{Concerns on the environmental impacts of buildings}

Respondents were asked the question: "Do you worry about the impact our buildings and energy usage has on the environment?" Although it was clear that protecting the environment was important to the residents it was good to see that $69 \%$ of residents were also worried about the impact their building and energy usage is having on the environment. Although this percentage is lower it is still good as typically people are concerned about the environment but don't consider their own impact on the environment. It is also important to consider that although $69 \%$ of residents were worried about their impact on the environment, of the remaining residents $14 \%$ were not worried about their impact and $17 \%$ were unsure what they thought.

\section{Willingness to accept}

Respondents were asked the question: "Would you like your residence to be more environmentally friendly?" One of the most important areas to gain some knowledge was with regards to whether the residents would like to see their homes become more environmentally friendly. Of the residents surveyed 58\% said they would like to see their homes become more environmentally friendly. Only $16 \%$ of respondents were against the idea, with the remaining $26 \%$ unsure of their position on the topic.

\section{Willingness to pay}

Respondents were asked the question: "Would you be prepared to pay a higher price for a home that has environmentally friendly features?" Although it was quite clear that the majority of residents want to live in an environmentally friendly home it was also made quite clear that the residents didn't want to pay more for it. When asked if they would be prepared to pay more only $23 \%$ of residents surveyed said they would be prepared to pay more, $43 \%$

Barker, J., Xia, B., Zou, J. and Zillante, G. (2012) 'Sustainable retirement living: what matters?', Australasian Journal of Construction Economics and Building, Conference Series, 12 (1) 56-61 
indicated that they were against the idea and the remaining 34\% were unsure of their position. This will be a key piece of information considering that typically environmentally friendly solutions will increase the final cost of dwellings.

\section{Incorporation of solar power generation}

As many elderly people are often apprehensive about new and different things it was quite surprising that the majority of residents surveyed indicated that they would not be concerned at all if solar power generation was integrated into their power supply system. In fact $61 \%$ of resident said they were not at all worried if solar power generation was used throughout their residence. Only $8 \%$ of residents said they were strongly concerned, with $16 \%$ indicating that they were slightly concerned about the implementation of solar power generation. The remaining $16 \%$ were unsure of their position on the topic.

\section{Experience with solar power}

The result of $61 \%$ of residents that were not at all worried about the implementation of solar power generation was very surprising considering that the majority of residents have had little experience with this technology. In fact $68 \%$ of residents surveyed had never had any experience with small scale solar power generation.

\section{Reduction of water usage}

Respondents were asked whether or not they would like to see their community reduce and recycle water usage. It was encouraging to see the responses to this question. $86 \%$ of residents surveyed said they would like to see the recycling of water to reduce water usage. With 5\% indicating that they were against the idea and the remaining $8 \%$ unsure what they thought. Respondents has highlighted it is mainly due to on-going drought conditions water restrictions have been applied throughout South Australia.

\section{Reuse of building materials}

Respondents were asked the question: "Many building materials rely heavily on our natural resources to be made. Environmentally friendly materials are available but are often more expensive. Would you like to see these materials used in and around your home?”

The results received from this question showed that $60 \%$ of residents would like to see more environmentally friendly materials used in the construction of their buildings. Only $9 \%$ of respondents were against the idea with the remaining 31\% unsure if they were for or against the idea.

\section{Energy saving at home}

Based on the responses received with regards to solar power generation, water harvesting and environmentally friendly materials it was important to understand if the residents of retirement living currently have the ability or opportunity to save energy around the home and also the facilities to recycle household waste. When posed with this question $59 \%$ of respondents said they were able to. Twenty-two\% of residents said they were unsure if they were currently able to save energy and the remaining $8 \%$ said they were unable to currently save energy.

Barker, J., Xia, B., Zou, J. and Zillante, G. (2012) 'Sustainable retirement living: what matters?', Australasian Journal of Construction Economics and Building, Conference Series, 12 (1) 56-61 


\section{Availability of facilities to recycle household waste}

In regards to this question a majority of $78 \%$ of residents indicated that they do have the facilities to recycle. $8 \%$ of respondents commented that they don't have the facilities to recycle and the remaining $14 \%$ unsure whether they had the facilities to recycle.

\section{Conclusions}

This study surveyed selected residents of retirement villages in South Australia in order to explore their awareness and attitudes to environmental sustainability of retirement living. The survey results showed that the majority of residents will be generally happy to embrace most environmentally friendly designs on the provision that the house costs or rental charges do not increase from the current level. Therefore the affordability remains a critical issue in providing sustainable housing to seniors. The cost of energy supply is a concern to the majority of residents. These findings provide useful inputs to design process as there will be flexibility as to what environmentally friendly technologies or techniques can be incorporated.

Considering that $40 \%$ of residents were either unsure or unable to save energy in their home, this is one area which could be addressed through the training of residents so they will be aware of some energy saving techniques. Similarly, most residents are open to the use of water recycling and solar power technologies in their homes. Education may be useful about recycling household waste and how to use available facilities. Developers are recommended to incorporate further recycling facilities into the retirement living units so that more day to day household waste could be recycled.

Limitations of this study belong to the comparatively small scale of the questionnaire survey where respondents were randomly drawn from residents of retirement villages developed by the ECH Incorporated. Future research opportunities exist to conduct a large scale survey at national level and include other stakeholders, e.g. developers, facility managers, government authorities. Similarly, social aspects of sustainability and affordability issues need to be considered comprehensively together with environmental aspects of sustainability in retirement villages.

\section{Acknowledgement}

This study is funded by the Education Trust of the Royal Institute of Chartered Surveyors (RICS), Award 449.

\section{References}

Australia Bureau of Statistics (ABS) (2010). 'Population by age and sex', Australian States and Territories, retrieved from: http://www.abs.gov.au/ausstats/abs@.nsf/mf/3201.0. $<$ June 2011>.

Chan, E.H.W., Qian, Q.K. and Lam, P.T.I. (2009). “The market for green building in developed Asian cities - the perspectives of building designers.” Energy Policy, 37(8), 3061-3070.

GBCA (2012). Green Star Rating Tools, retrieved from: http://www.gbca.org.au/greenstar/rating-tools/, accessed online, $<$ February $10^{\text {th }} 2012>$.

Barker, J., Xia, B., Zou, J. and Zillante, G. (2012) 'Sustainable retirement living: what matters?', Australasian Journal of Construction Economics and Building, Conference Series, 12 (1) 56-61 
Ilha, M., Oliveira L. and Goncalves, O. (2009). 'Environmental assessment of residential buildings with an emphasis on water conservation.' Building Services Engineering Research and Technology 30, 15-26

McCormack, M., Treloar, G.J., Palmowski, L. and Crawford, R. (2007). Modelling direct and indirect water requirements of construction.' Building Research \& Information, 35, 156162.

RVA (2011) A sustainable population strategy for Australia, Submission to the Department of Sustainability, Environment, Water, Population and Communities, Retirement Village Association, March 2011.

Retirement Village Association and Aged and Community Services Association of NSW and ACT (2010) Retirement Villages Bill 2010 (ACT), retrieved from: http://www.agedservices.asn.au/wp-content/uploads/2009/11/ACT-LegislationSubmission-090810.pdf, <June 2011>.

Tam, V.W.Y. (2008), 'Economic comparison of concrete recycling: a case study approach.' Resources, Conservation and Recycling, 52, 821-828.

WBCSD (2007). Energy Efficiency in Buildings, Business realities and opportunities, the World Business Council for Sustainable Development.

WBCSD (2010) Vision 2050: The new agenda for business, World Business Council for Sustainable Development, February 2010.

Zuo, J., Read, B., Pullen, S. and Shi, Q. (2012). 'Achieving carbon neutrality in commercial building developments - Perceptions of the construction industry.' Habitat International, 36, 278-286. 